\title{
Fuel Oil Resources of the Future.
}

\section{By H. B. Milner.}

PUBLIC attention has once again been directed to the vital question of the world's' resources of petroleum, in a paper read before the Institution of Petroleum Technologists by Prof. A. W. Nash and Mr. H. G. Shatwell on December 2, and further by a column having reference to that communication in the Times of December 3. The object of the paper is to allay uneasiness existing in the minds of many with regard to the adequacy of future oil resources.

The argument requires that before justifiable fears are entertained we must be satisfied that all free petroleum in the earth has been located, that the problem of the origin of petroleum has been solved, and that "oilfields can be discovered and not simply located as a result of surface workings by local inhabitants." Alternative to natural mineral oil are " the abundant stores of bituminous material from which oil can be obtained by destructive distillation," these being oil shales, cannel coals, torbanites, lignites, peat, and coal.

With regard to the first point, it is maintained that outside America the search for oil has not been carried on diligently, and the implication is that, following precedent in the history of the American oil industry, more fields should be developed in other countries. Then, the problem of the origin of petroleum not having been solved to general satisfaction, it is argued that it is impossible to state definitely that oil is not in process of formation at the present time. The third point is obscure both in definition and in amplification, though it is implied that improved technique is necessary in the initial stages of oil exploration. The arguments in favour of the development of alternative fuel resources are not new, though great stress is laid on the commercial possibilities of " berginisation" of coal and oil as a promising method of obtaining a substitute for natural petroleum.

It is difficult, despite the good case made out by the authors for peace of mind in connexion with future oil supply, to share fully their optimism, because while some agreement may be accorded with the facts they adduce in support of their opinions, their interpretation of the position and the conclusions they reach, since they are based on no new data, are open to question as much from economic as from technical points of view.

Misapprehension concerning the future of oil-fuel supplies was first of all felt and voiced, not by an irresponsible section of the community, but by experts both in the United States and in Europe, who realised the true drift of events. Far-sighted people, from an examination of the position from every angle-national, technical, economic-gradually came to see that if production did not keep pace with an ever-growing consumption, a most serious position would arise, probably within the course of two decades or so. Uneasiness spread, therefore, despite insistent press contradictions, instigated by interested persons, who did not hesitate to write up glowing accounts of a contemporary " oil age," and to quote misleading statistics to prove their optimistic contentions. Thus the industry and the public were entitled to an unbiassed knowledge of the facts, and also to considered and authoritative judgment on the position, either as a clear warning to be prepared for the worst, or as a vindication of the lighthearted optimism expressed in some quarters. The authors have therefore done well in bringing the matter once more to the front, even though we cannot agree with the reasons they consider sufficient to disarm fear for the future.

First, it is, we agree, reasonable to believe that all available petroleum has not yet been located; it would indeed be a poor outlook if this were so. But it is a question of magnitude of resources to be tapped, not merely the discovery of several comparatively small oil-pools. We have to ask ourselves whether, from broad geological knowledge of the world, there exist accessible regions outside the United States, where geological conditions are likely to favour the preservation of oil deposits on the vast scale which has made the industry in that country, and latterly in the world, what it is? Can we point to a second Pennsylvanian, Mid-Continent, or Californian region anywhere with any degree of scientific possibility? It is difficult to do so. It is, of course, possible to predict many localities likely to yield a future oil supply, on a par with, say, Persia, or Sarawak, at the present time, but it is not easy to visualise the existence of oil-pools the collective exploitation of which will determine an ultimate supply on the scale at present requisite, or likely to be demanded in the near future, if and when the United States with Mexico cease to yield 8o per cent. of the world's total output.

Secondly, we may agree with the authors that the mode of origin of petroleum still remains debatable, despite more than thirty years of philosophy, but even if the problem were solved to universal satisfaction to-morrow, would the knowledge lead us to the location of deposits at present forming, and would such deposits be likely to have immediate eeonomic value even if they were found? Whatever theory be advanced to account for the origin and accumulation of petroleum, the geological time-factor seems to be an inevitable influence in the mechanism, and yet we are asked to contemplate the prospect of contemporary petroleum, ripe for use, if not just at the moment, at least within the next few decades! An accepted solution of the genesis of petroleum is desirable for many reasonsmainly scientific - but the immediate economic significance of such a solution if arrived at, as indicative of a new line of field-investigation, is difficult to follow.

Thirdly, the authors suggest that mere geological examination of potential oil-bearing territory is insufficient, and should be accompanied at the outset by a drilling staff " to drill for geological information and not for oil." Where is the philanthropic company which can be persuaded to finance such a proposition? Further, the platitude is expressed that the science of geology of petroleum is an inexact one ; since geology itself cannot be classed as an exact science, obviously a particular application must, a priori, be inexact. But is it a whit more precise, as is implied, to encourage wholesale "wild-catting" of a kind which, while admittedly advisable from the purely technical aspect of fieldgeology, might only result in more failures to find oil, certainly in a heavier initial expenditure which the

$$
\text { NO. } 2879 \text { vOL. I I } 5]
$$


average company director would never agree to incur, not even in these enlightened days of intelligent directorates? If the geologist is to be of any use at all in locating oil deposits, his work must precede exploratory drilling, for economic, if for no other reasons.

The authors also review the existing position of oil supply and mention more particularly possibilities in Persia. In this connexion, while sharing their opinion, we may be allowed the remark that eyen if Persia doubles her production in the next year or two, it would only represent 5 per cent. of the world's output at the present rate. They also stress the potentialities of the Canadian Athabasca tar-sands, a proper utilisation of only 25 per cent. of which would, they say, remove apprehension regarding the future. We refer them to the recent report by S. C. Ells (Bituminous Sands of Northern Alberta, 1924), in which he states (in reference to tar-springs) that " in no instances are they themselves of commercial value as a source of bitumen. They have, at times, been regarded erroneously as a definite indication of the presence of petroleum pools." Later, summarising several processes devised for producing oil from these tar-sands, he says, "The results of this work are as yet inconclusive."

A further " off-set" to shortage of supply is the possibility of mining for recoverable oil from abandoned oil-fields by shafts and galleries, as at Pechelbronn; this principle, apart from the human factors involved, may be economic with shallow sands in some cases, but what of oil-sands lying between 3000 and 5000 feet below the surface: would the method be practicable, and does it therefore help the solution of the difficulty?

Lastly, we reach the question of alternative fuel resources, and here, while the authors are to be congratulated on the way they have marshalled the possibilities of shales and coals, they should in fairness have laid more stress on the technical difficulties at present in the way of utilising these resources on a satisfactory commercial scale. The world's known resources of oil-shale are now generally appreciated, but the estimates given by Alderson and others as to the amount of oil recoverable from them are quite fictitious until suitable retorts and processes are devised for treating them economically, while apart from any other difficulty, desulphurisation of shale-oil and high refining losses still remain in many cases thorny impediments to development, as in Great Britain.

The difficulties concerned with coal and allied carbonaceous material as a source of oil are similarly those concerned with large-scale treatment for commercial supply. Low temperature carbonisation is, from the economic point of view, a process which has yet to be extended under modern conditions of fuel supply and efficiency. Even if successful, oil thus obtained, as the authors admit, can never adequately replace petroleum products. The "berginisation" of coal and oil, regarded by the authors as being of great promise, is in an experimental stage, and much ground has yet to be covered before the application is a practicable one from a commercial point of view. This process consists in heating in the presence of hydrogen a mixture of powdered coal containing less than 85 per cent. of carbon, with mineral oil or tar oil at high pressure (Ioo atm.) and temperature $\left(400^{\circ}-430^{\circ} \mathrm{C}\right.$.), when a liquid product closely resembling petroleum results. It may be pointed out that unless the liquid product is capable on refinement of yielding a range of products which will take the place of petrol, kerosene, lubricating oil and fuel oil, the process loses at once in value as a means of producing artificial fuels. At present we have little trustworthy data concerning either the refinement or the quality of such " berginised" oil.

Thus the whole question remains in an unsatisfactory position, and it cannot be said that a critical examination of the authors' thesis advances things much further. We endorse, as every student of science will do, their insistence on the need for research, not only for posterity, but also for our own sakes. Conservation of petroleum resources will automatically come, whether we urge it or not, since for strategic reasons alone the United States will ultimately have to limit its exports of oil, and that, too, within the next two decades, if further large supplies are not forthcoming. Once the United States decides on that policy, Europe' and all other countries dependent on it for the larger proportion of their oil-fuel requirements will have to face the inevitable, and either economise in the use of petrol and petroleum products, or provide some alternative, but probably in the long run; far less convenient fuels and lubricants.

Hence the keynote to the situation may be summed up in the word economy. The present heavy-handed use of petroleum results from a general impression that there is plenty more where the present supply comes from, an extravagant idea inculcated by the same policy responsible for recent deplorable overproduction and wasteful consumption. If the industry, by adopting in the future the practice of husbanding existing resources and by straining every scientific nerve to a higher technique in production, refinement and utilisation of oil-fuel, thus sets the example to the public, the public itself will be educated. Decline in cumulative production in such circumstances will be slow; the full and beneficial effect of each new discovery of an oil-pool, however small, will also have time to operate, and the gaining of time in one way means that the chances of developing new schemes of alternative fuels, as outlined by the authors, are more likely to meet with success, at all events as commercial propositions.

Some people hold that we should enjoy the gift bestowed on our own generation, the privilege of living in an "oil age," and leave posterity to take care of itself. This is neither a credit to contemporary knowledge, nor is it in keeping with the best traditions of scientific progress. We owe it to ourselves to face the situation as repeatedly exposed by David White, Pogue, and others qualified to judge, and whatever position may ultimately be created by a shortage of natural petroleum, we have to see that we are not unprepared to meet the contingency either through lack of foresight or of initiative in perfecting substitutes. But we have also to realise that the prospect of supplanting petroleum by alternative, artificial fuels is confined largely to the realm of experimental possibilities; merely to define the possibilities is not necessarily to remove the qualms which still exist in the minds of not a small section of workers in the oil industry.

$$
\text { NO. } 2879 \text {, vOL. I I } 5 \text { ] }
$$

